\title{
Highly crystalline mesoporous titania loaded with monodispersed gold nanoparticles: controllable metal-support interaction in porous materials
}

\author{
Lei Jin, ${ }^{1}$ Ben Liu, ${ }^{1,3}$ Michael E. Louis, ${ }^{4}$ Gonghu $\mathrm{Li}^{4 *}$ and Jie $\mathrm{He}^{1,2^{*}}$ \\ ${ }^{1}$ Department of Chemistry, and ${ }^{2}$ Polymer Program, Institute of Materials Science, University of \\ Connecticut, Storrs, CT 06269, United States; ${ }^{3}$ Jiangsu Key Laboratory of New Power Batteries, Jiangsu \\ Collaborative Innovation Center of Biomedical Functional Materials, School of Chemistry and Materials \\ Science, Nanjing Normal University, Nanjing 210023, China; ${ }^{4}$ Department of Chemistry, University of \\ New Hampshire, Durham, NH 03824, United States \\ * To whom correspondence should be addressed. Email: jie.he@uconn.edu (JH) and gonghu.li@unh.edu \\ (GL)
}

\section{Figure Contents}

Figure S1. ${ }^{1} \mathrm{H}$ NMR spectrum of PEO- $b$-PTMSPMA and the TEM image of corresponded CAMs templates.

Figure S2. Extra SEM images of $\mathrm{Au} @ m \mathrm{TiO}_{2}-800$.

Figure S3. TEM images and size distribution of as-made AuNPs.

Figure S4. STEM-EDS of $\mathrm{Au} @ m \mathrm{TiO}_{2}-800$.

Figure S5. Wall thickness of $\mathrm{Au} @ m \mathrm{TiO}_{2}$.

Figure S6. SAXS patterns of $\mathrm{Au} @ m \mathrm{TiO}_{2}-600$.

Figure S7-S10. ${ }^{1} \mathrm{H}$ NMR spectra showing the photocatalytic oxidation of benzyl alcohol.

Figure S11. Catalytic stability of $\mathrm{Au} @ m \mathrm{TiO}_{2}-600$.

Figure S12. SEM images and pore size distribution of $m \mathrm{TiO}_{2}-600$.

Figure S13. EPR spectra of $m \mathrm{TiO}_{2}-600$ and $\mathrm{Au} @ m \mathrm{TiO}_{2}-600$.

Figure S14. Photocurrent of different catalysts under visible light.

Figure S15. DRIFTS Spectra of CO adsorbed on $\mathrm{Au} @ m \mathrm{TiO}_{2}-600$-t.

Table S1. SAXS patterns analysis. 

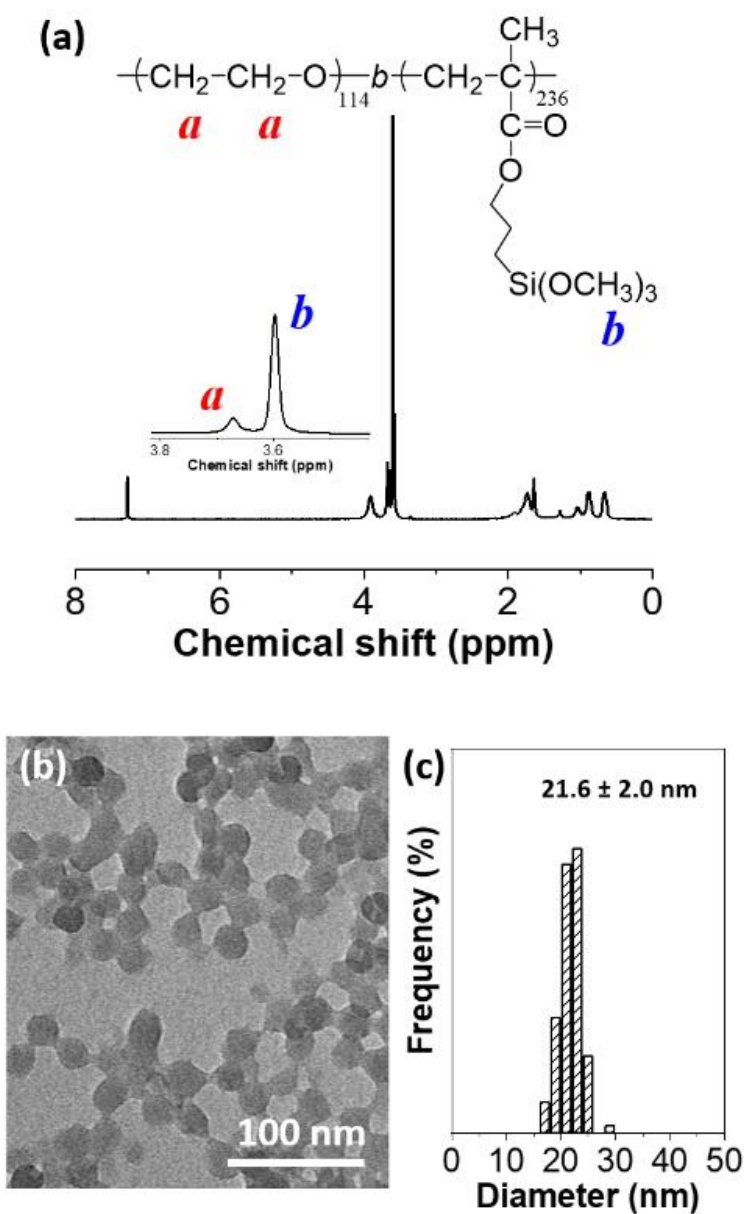

Figure S1. (a) ${ }^{1} \mathrm{H}$ NMR spectrum of PEO-b-PTMSPMA. (b) SEM image, and (c) corresponded size distribution of CAMs templates. 

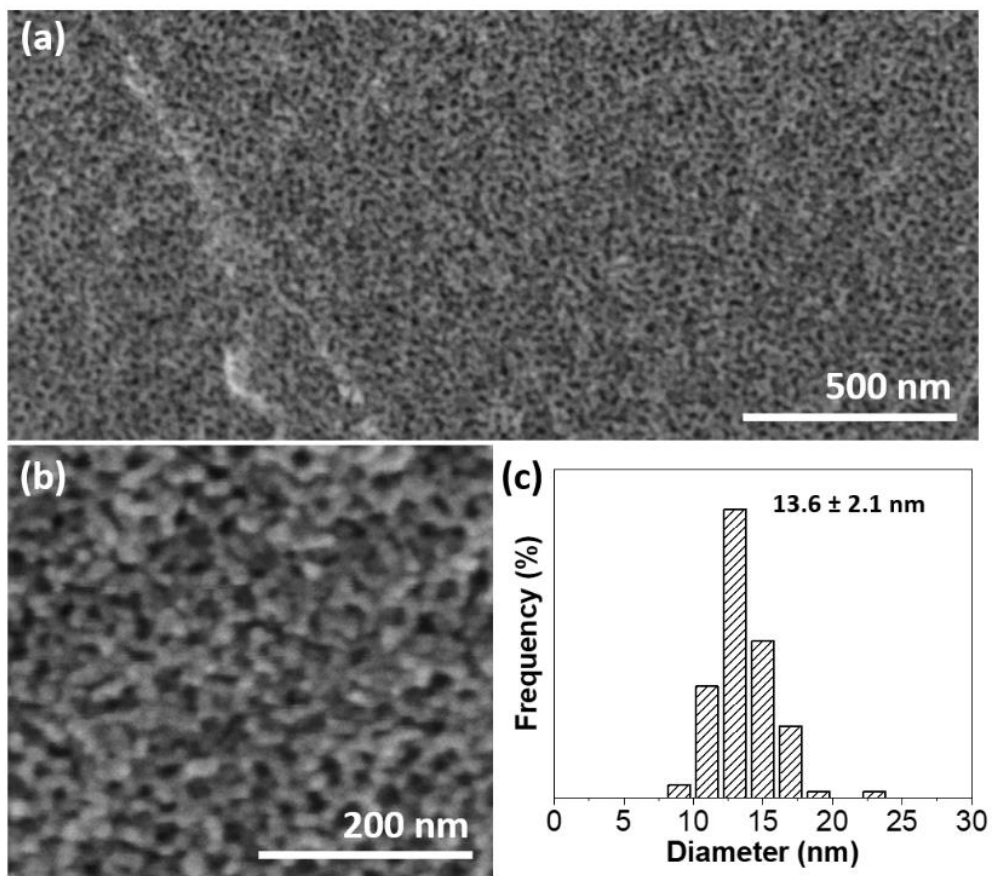

Figure S2. (a-b) SEM images and (c) corresponded pore size distribution of $\mathrm{Au} @ m \mathrm{TiO}_{2}-800$. 

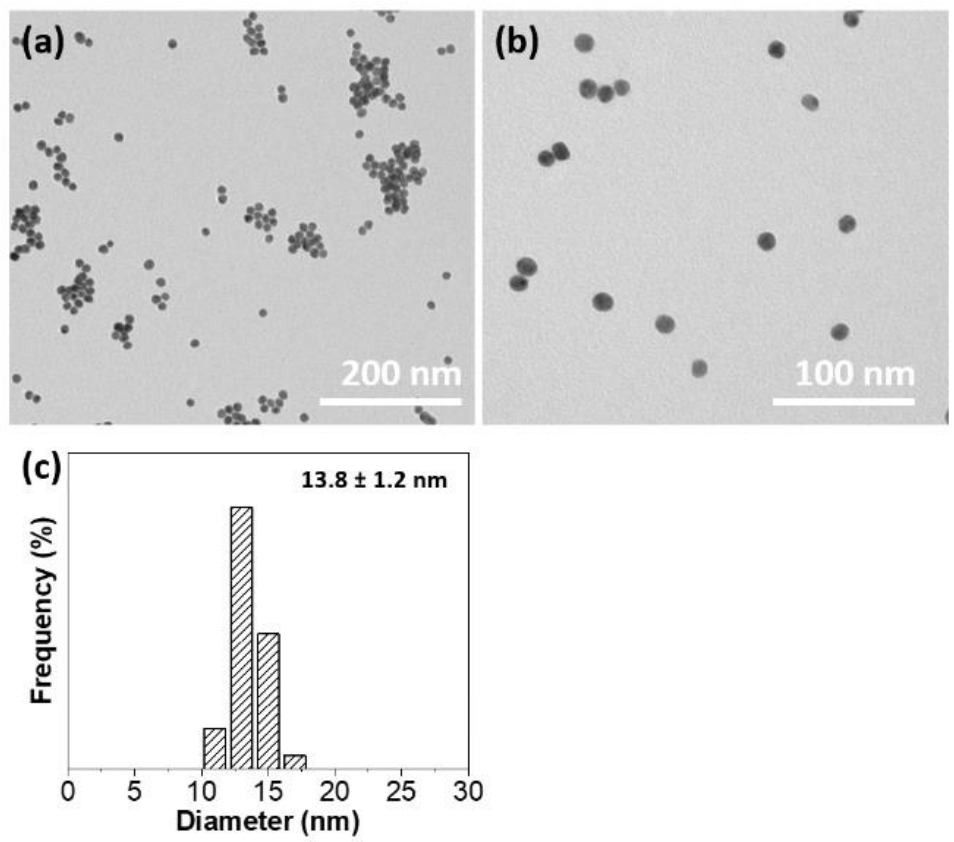

Figure S3. (a-b) TEM images of as-made AuNPs. (c) Size distribution of AuNPs. 


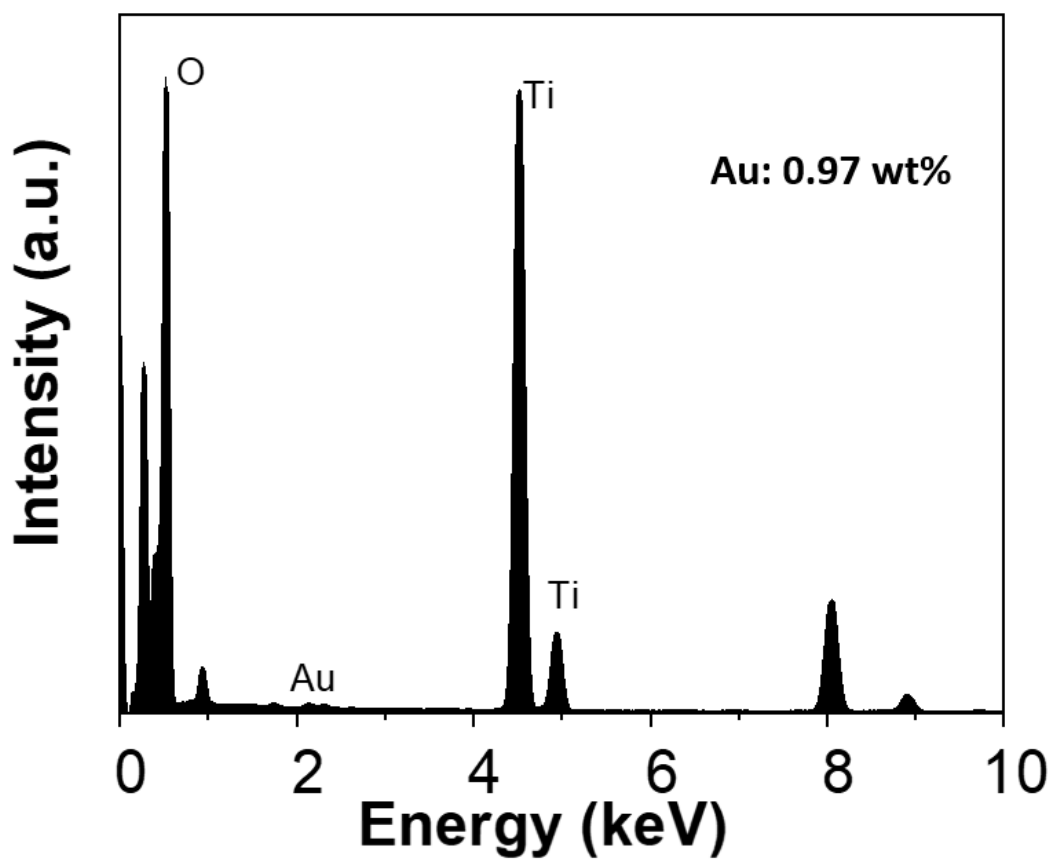

Figure S4. STEM-EDS spectrum of $\mathrm{Au} @ m \mathrm{TiO}_{2}-800$. The loading amount of Au was estimated to be $0.97 \mathrm{wt} \%$. 

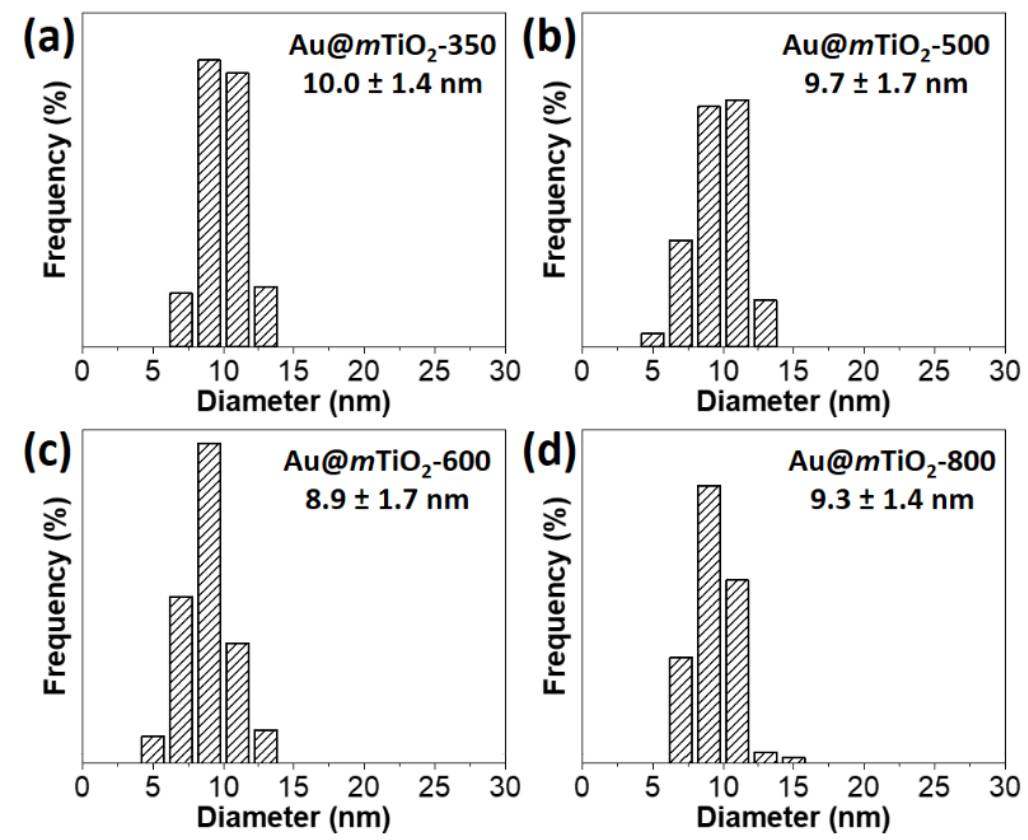

Figure S5. Wall thickness of (a) $\mathrm{Au} @ m \mathrm{TiO}_{2^{-}}-350$, (b) $\mathrm{Au} @ m \mathrm{TiO}_{2^{-}} 500$, (c) $\mathrm{Au} @ m \mathrm{TiO}_{2^{-}} 600$, and (d) $\mathrm{Au} @ m \mathrm{TiO}_{2^{-}}$ 800 


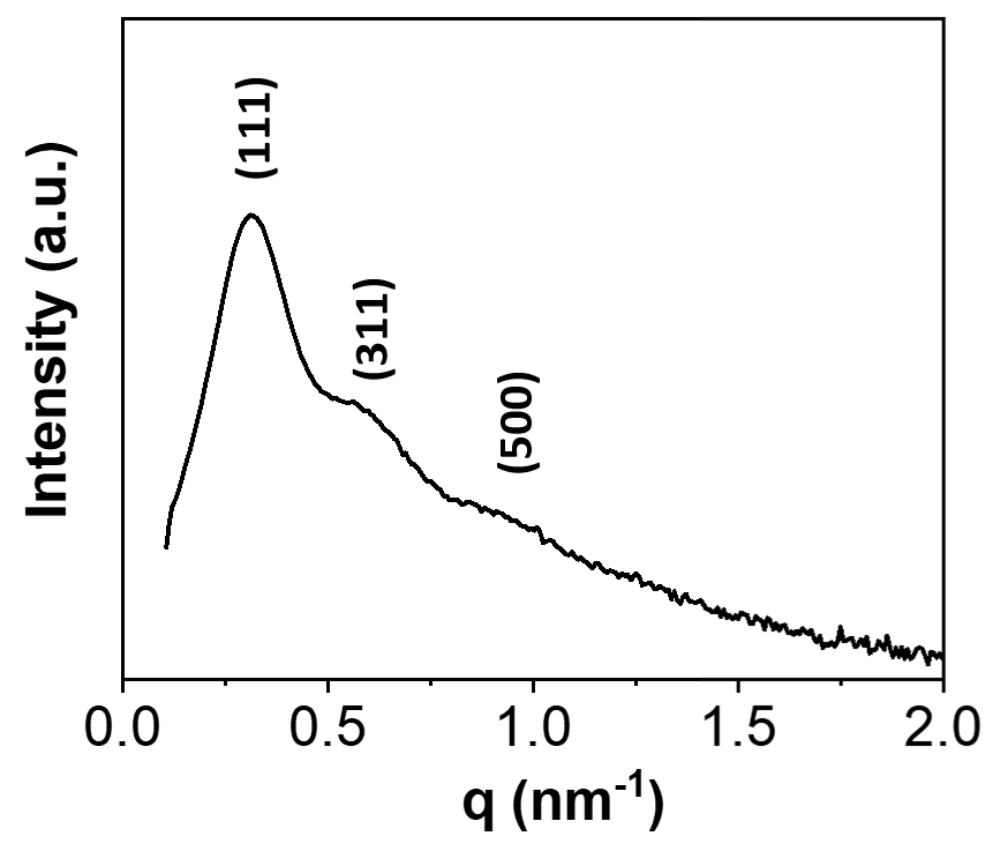

Figure S6. Small angle X-ray scattering of $\mathrm{Au} @ m \mathrm{TiO}_{2}-600$. 


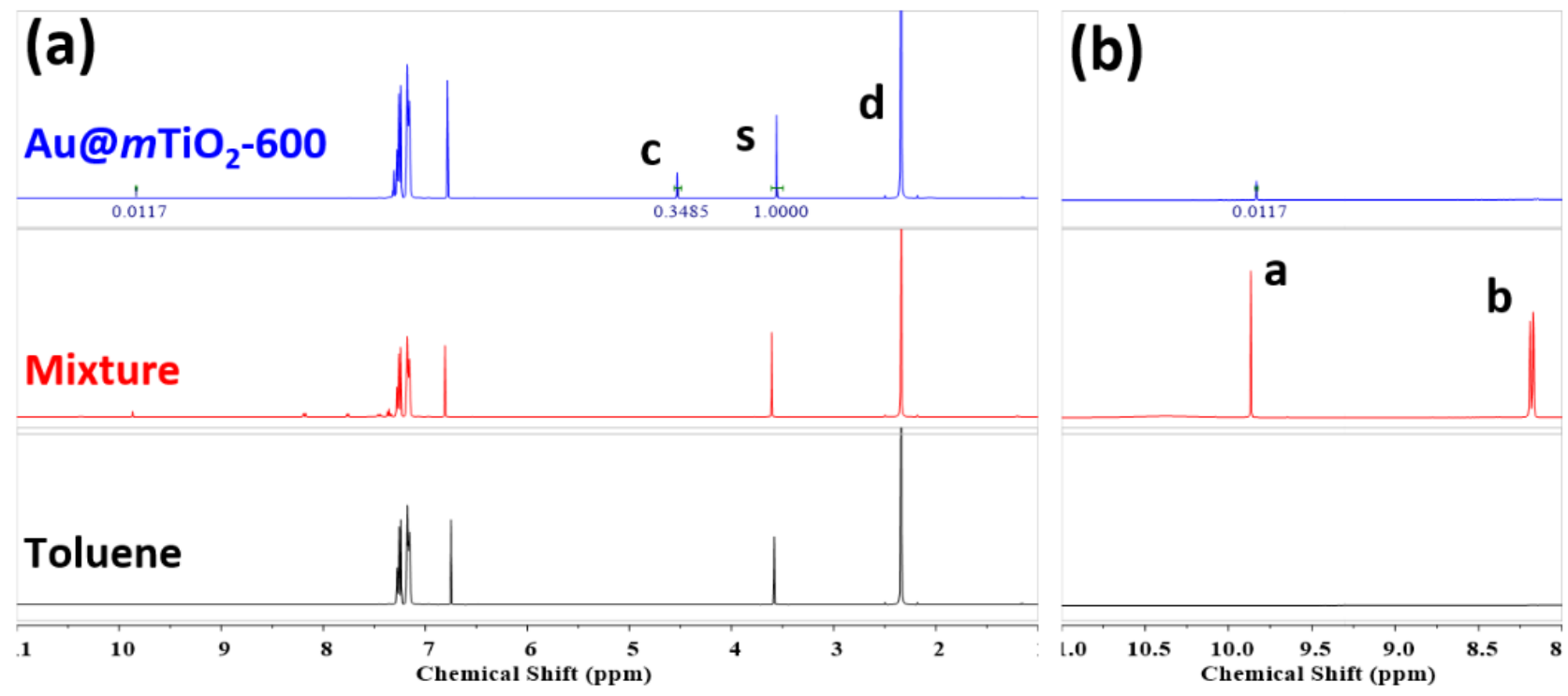

Figure S7. (a) ${ }^{1} \mathrm{H}$ NMR spectra of toluene, mixture (toluene, benzaldehyde, and benzoic acid), and the reaction catalyzed by Au@m $\mathrm{TiO}_{2}-600$ under UV light for 4 h. (b) Zoom-in spectrum of the product analysis using $\mathrm{Au} @ m \mathrm{TiO}_{2}-600$. Peak assignment: peak a. benzaldehyde $(9.86 \mathrm{ppm}, s, 1 \mathrm{H})$; peak b. benzoic acid $(8.19 \mathrm{ppm}, d$, $2 \mathrm{H}$ ); peak c. benzyl alcohol (4.53 ppm, $s, 2 \mathrm{H})$; and peak d. toluene (2.34 ppm, $s, 3 \mathrm{H})$. The peak s is from dioxane (3.61 ppm, $s$, internal standard). Benzaldehyde is the main liquid product without the formation of benzoic acid. The integrations of $\mathrm{Au} @ m \mathrm{TiO}_{2}-600$ are: a. 0.0140, c. 0.3422, and s. 1.0000. 


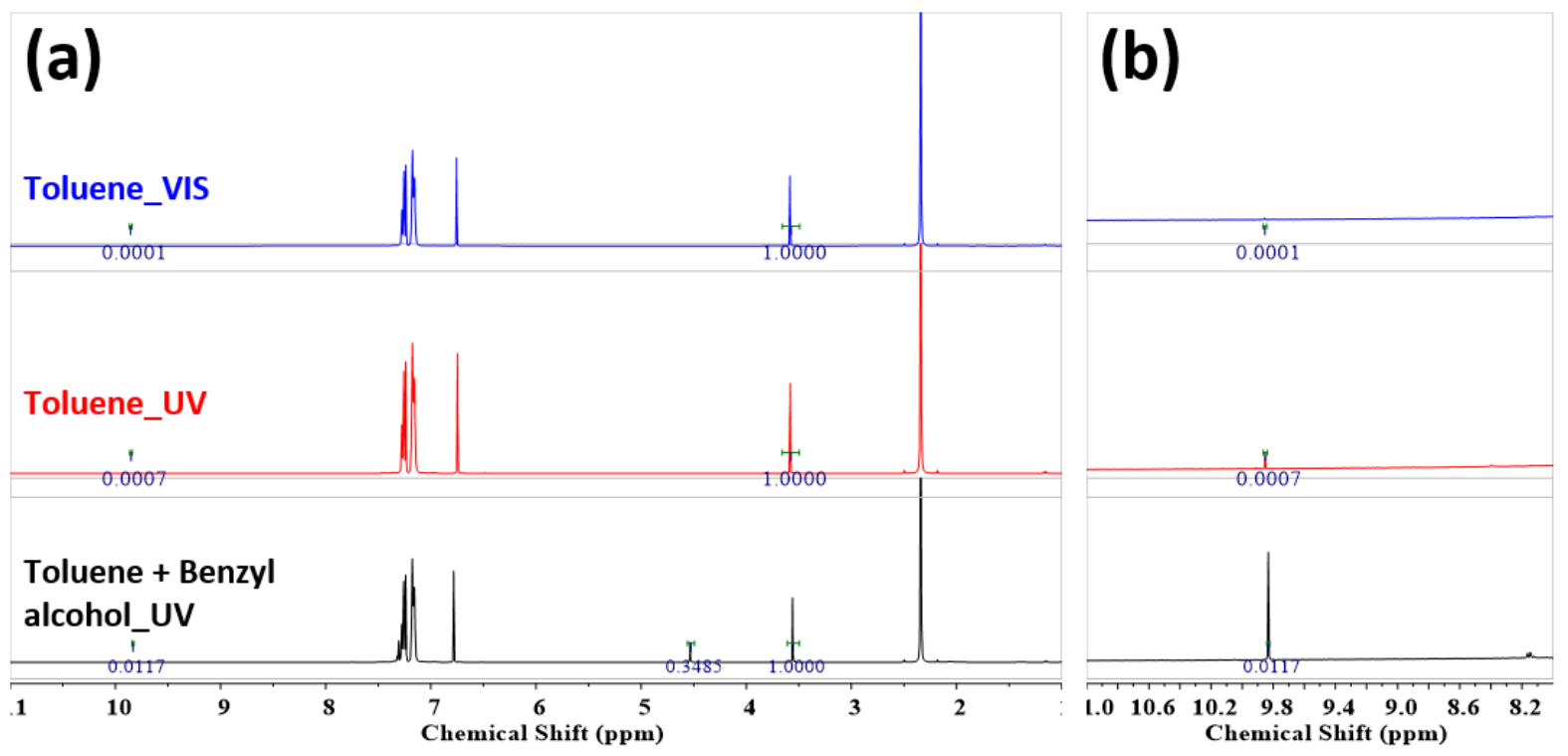

Figure S8. (a) ${ }^{1} \mathrm{H}$ NMR spectra of reaction mixture after $4 \mathrm{~h}$ using $\mathrm{Au} @ m \mathrm{TiO}_{2}-600$ as the catalyst with and without benzyl alcohol as the reactant. (b) Zoom-in spectra in the range of products. In the absence of benzyl alcohol, negligible benzaldehyde and benzyl alcohol were produced from the oxidation of toluene. 

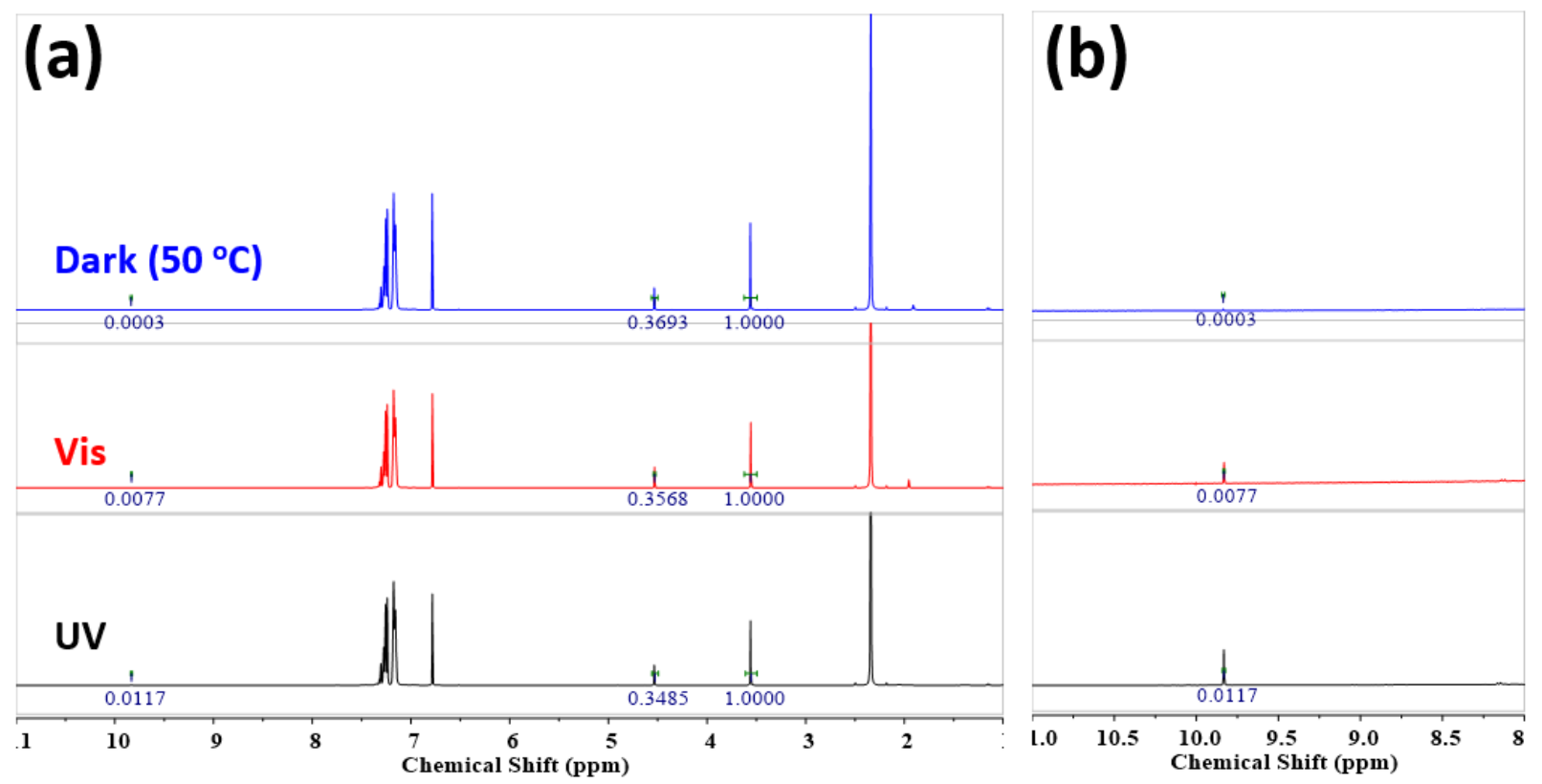

Figure S9. (a) ${ }^{1} \mathrm{H}$ NMR spectra of reaction mixture after $4 \mathrm{~h}$ using $\mathrm{Au} @ m \mathrm{TiO}_{2}-600$ under $\mathrm{UV}$ light, under visible light, and at $50{ }^{\circ} \mathrm{C}$ without light irradiation, respectively. (b) Zoom-in spectra showing the formation of benzaldehyde. The benzaldehyde formed from photo-thermal effect is negligible, compared with that generated from photocatalysis. 


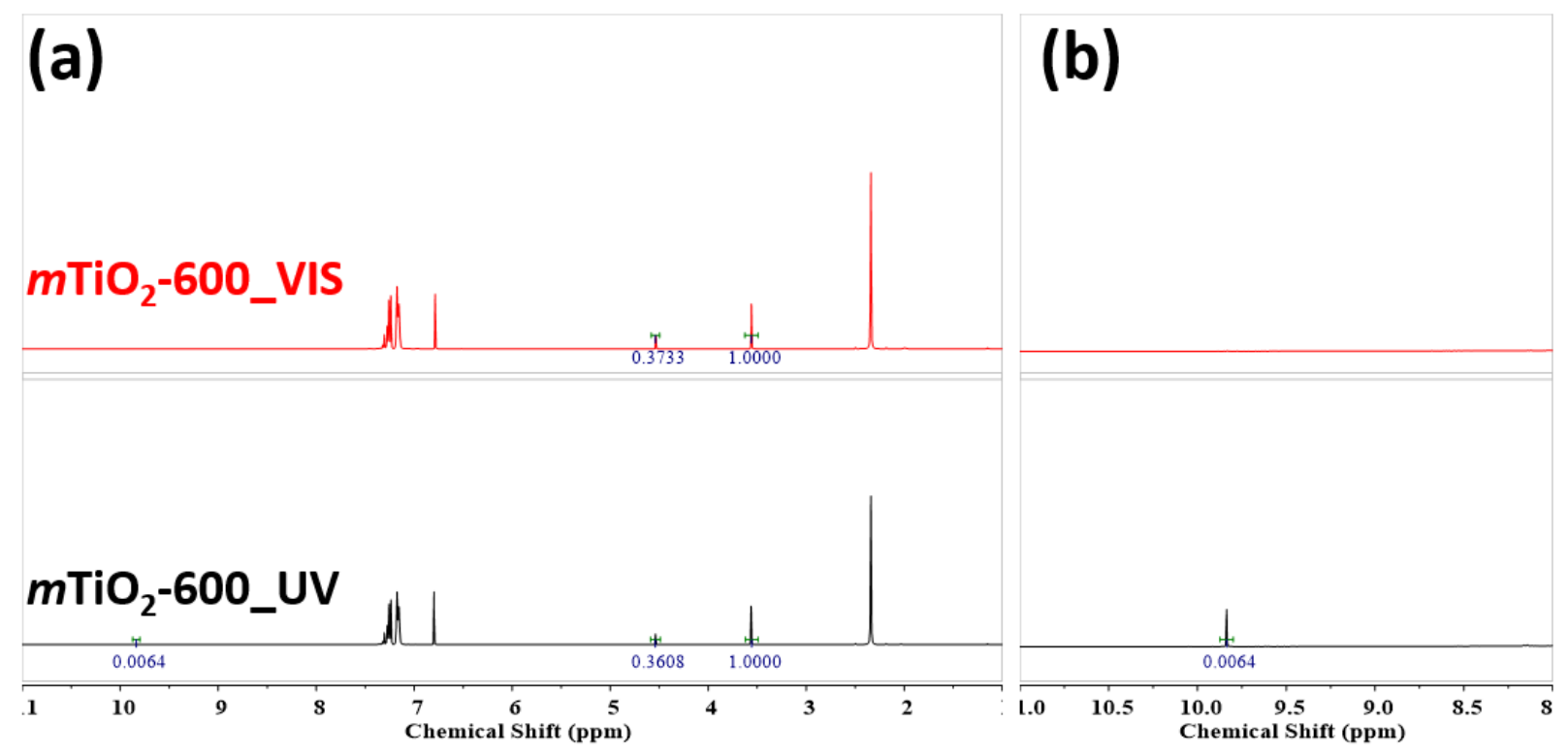

Figure S10. (a) ${ }^{1} \mathrm{H}$ NMR spectra of reaction mixture after $4 \mathrm{~h}$ using $m \mathrm{TiO}_{2}-600$ under UV light, and under visible light, respectively. (b) Zoom-in spectra showing the formation of benzaldehyde. 


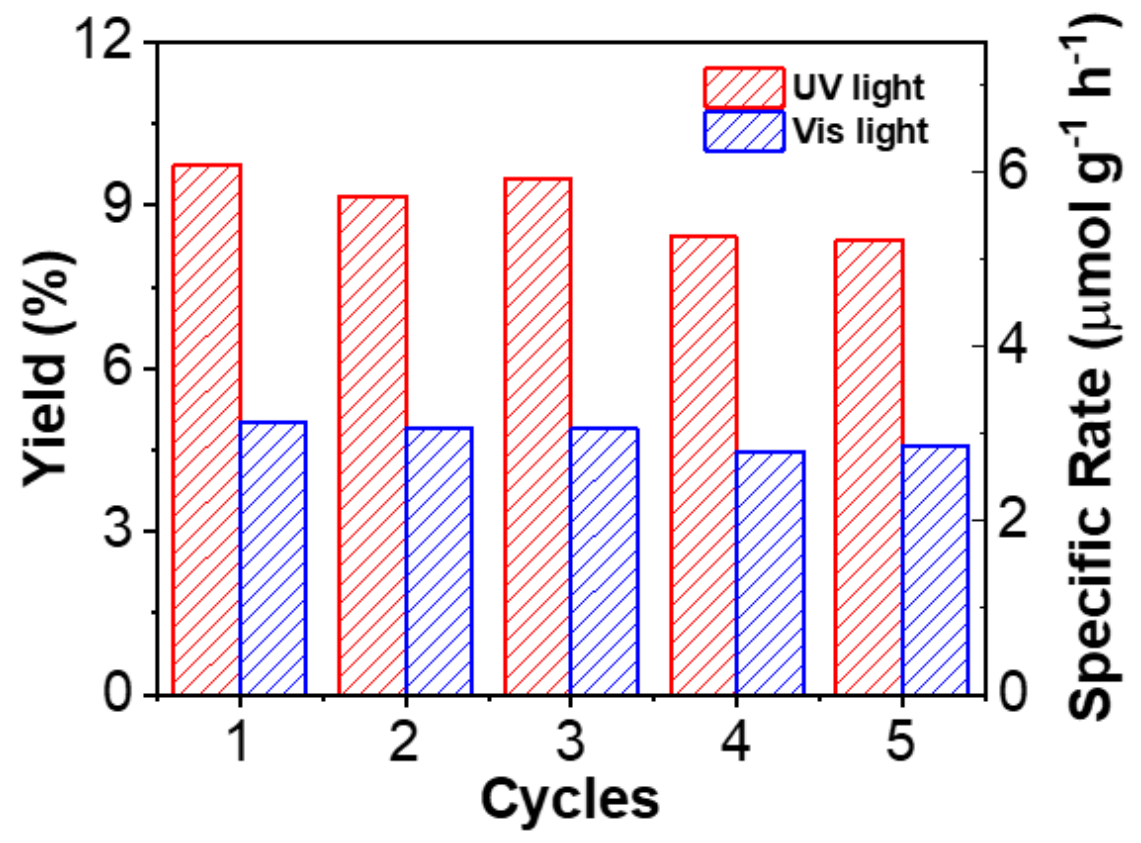

Figure S11. Catalytic stability test of $\mathrm{Au} @ m \mathrm{TiO}_{2}-600$ under UV light and visible light. 

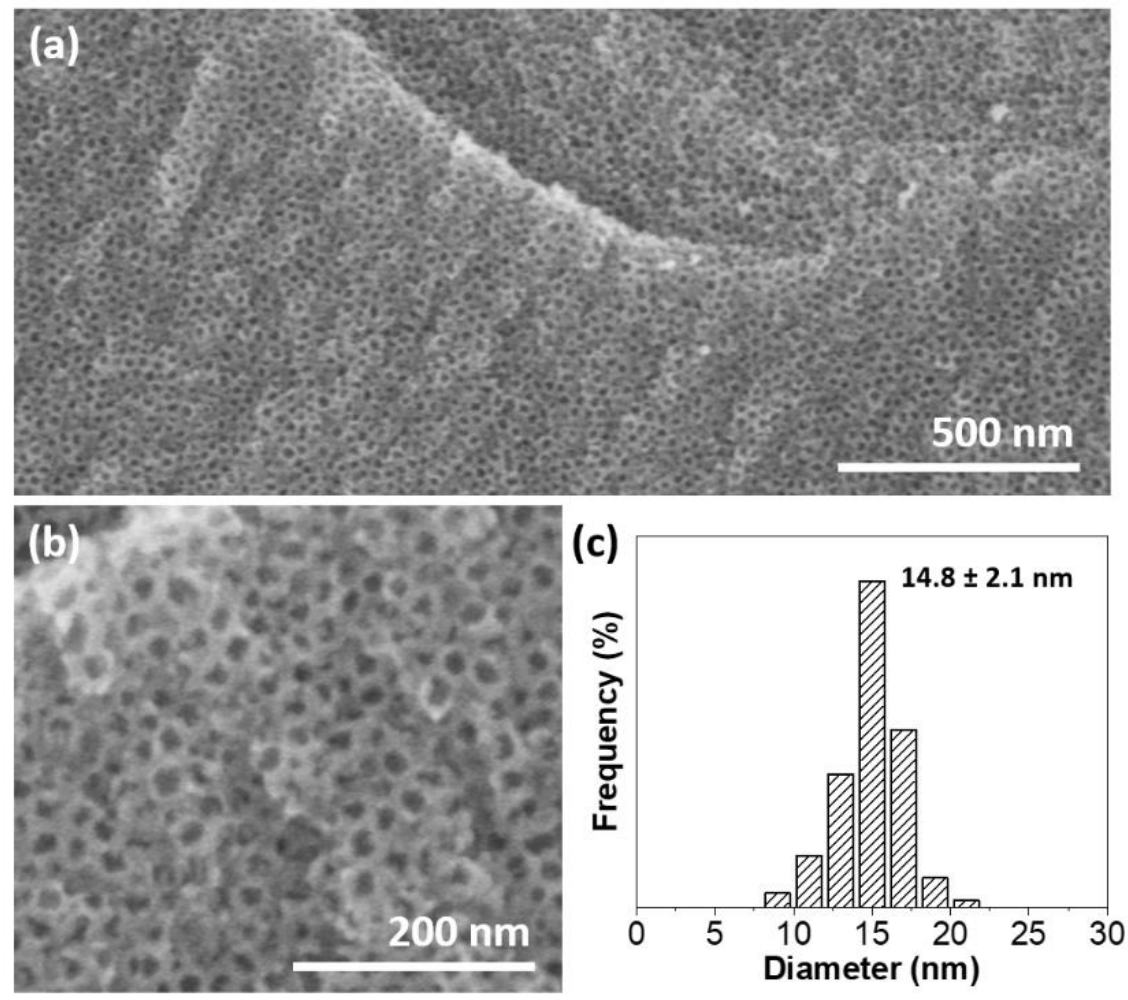

Figure S12. (a-b) SEM images and (c) size distribution of $m \mathrm{TiO}_{2}-600$ 


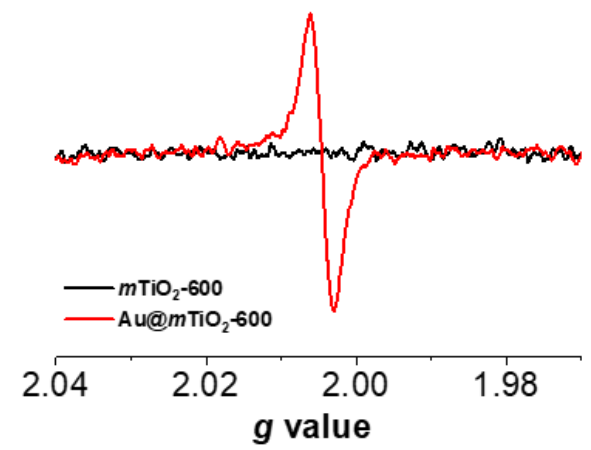

Figure S13. EPR spectra of $m \mathrm{TiO}_{2}-600$ and $\mathrm{Au} @ m \mathrm{TiO}_{2}-600$. 

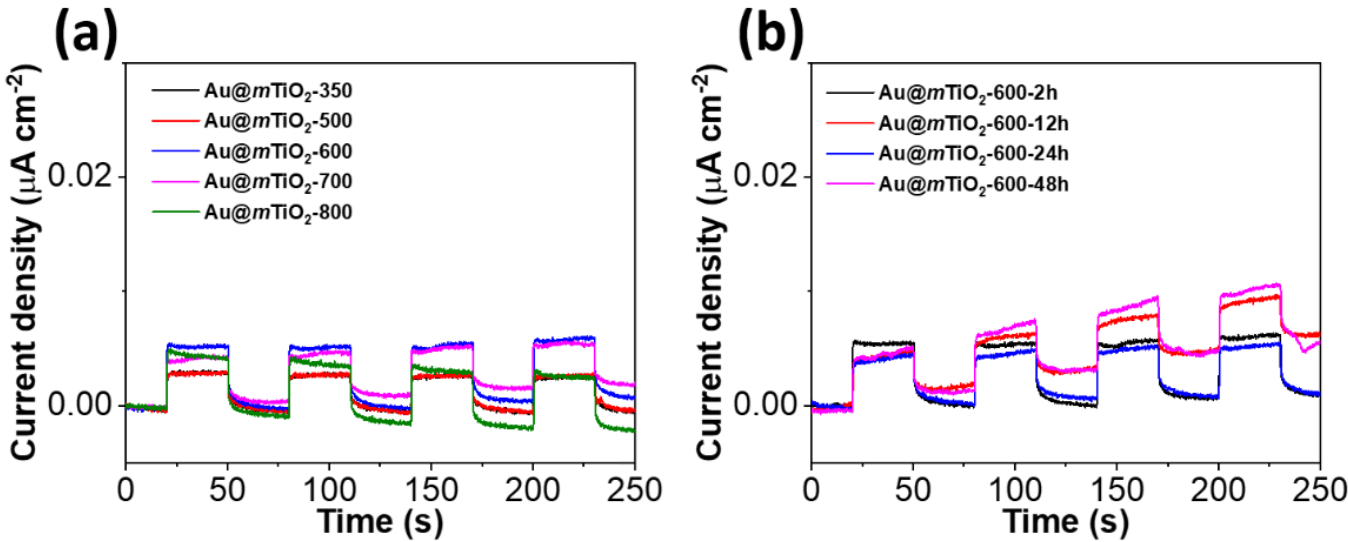

Figure S14. Photocurrent of (a) $\mathrm{Au} @ m \mathrm{TiO}_{2}-\mathrm{T}$, and (b) $\mathrm{Au} @ m \mathrm{TiO}_{2}-600$-t under visible light irradiation (500-600 $\mathrm{nm})$. 


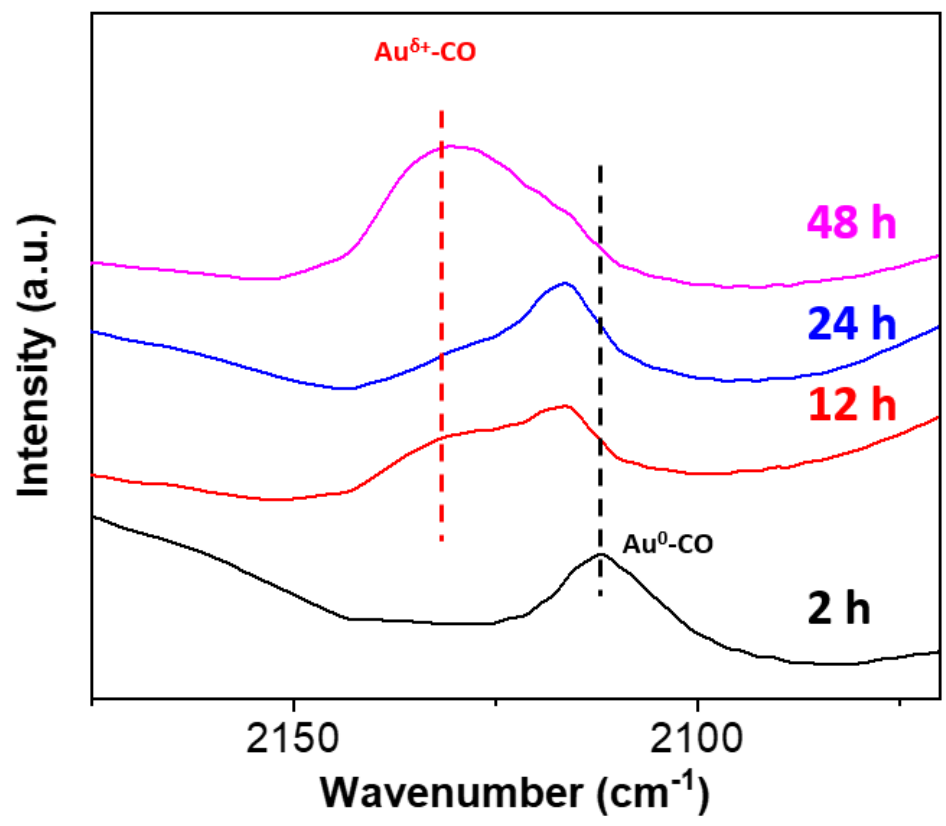

Figure S15. DRIFTS spectra of CO adsorbed on Au@mTiO ${ }_{2}-600-t$. The peak at $2112 \mathrm{~cm}^{-1}$ was assigned to CO adsorbed on $\mathrm{Au}^{0}$, which shifts gradually to the high wavenumber due to the metal-support interaction. The broad peak at round $2130 \mathrm{~cm}^{-1}$ was assigned to $\mathrm{CO}$ adsorbed on $\mathrm{Au}^{\delta+}$, which became the dominant peak when the calcination time is $48 \mathrm{~h}$. 
Table S1. Indexing of SAXS peak of Au@m $m \mathrm{TiO}_{2}-600$

\begin{tabular}{cccc}
\hline$(h k l)$ & $q\left(\mathrm{~nm}^{-1}\right)$ & $d(\mathrm{~nm})$ & $a(\mathrm{~nm})$ \\
\hline$(111)$ & 0.316 & 19.88 & 34.43 \\
$(311)$ & 0.611 & 10.28 & 34.10 \\
$(500)$ & 0.940 & 6.68 & 33.42 \\
\hline
\end{tabular}

The quantum yield of photocatalysts was estimated based on the produced benzaldehyde and the amounts of incident photons in the reaction system. The light intensity after passing through a $365 \mathrm{~nm}$ filter was measured to be $2.05 \mathrm{~mW} \mathrm{~cm}^{-2}$, with an effective area of $\sim 4 \mathrm{~cm}^{2}$. The yield of benzaldehyde was measured to be $4.96 \%$ for $\mathrm{Au} @ m \mathrm{TiO}_{2}-600$, and $2.08 \%$ for $m \mathrm{TiO}_{2}$ after $4 \mathrm{~h}$ reaction. The quantum yield can be calculated using the following equation: ${ }^{1}$

$$
\text { Quantum yield }(\eta)=2 \mathrm{~N}_{\text {benzaldehyde }} / \mathrm{N}_{\text {photons }}
$$

where $\mathrm{N}_{\text {benzaldehyde }}$ and $\mathrm{N}_{\text {photons }}$ are the numbers of produced benzaldehyde molecules and absorbed photons, respectively.

Take Au@m $m \mathrm{TiO}_{2}-600$ as an example, $\mathrm{N}_{\text {benzaldehyde }}$ was calculated as follows,

$$
N_{\text {benzaldehyde }}=\frac{n_{\text {benzaldehyde }} \times N_{A}}{t}=\frac{2.50 \times 4.96 \% \times 10^{-6}}{4 \times 3600 \mathrm{~s}}=5.19 \times 10^{12} \mathrm{~s}^{-1}
$$

where $\mathrm{n}_{\text {benzaldehyde }}, N_{A}$, and $t$ are the mole number of benzaldehyde, Avogadro constant, and the reaction time, respectively.

The energy $\left(E_{\text {total }}\right)$ from light irradiation was calculated as follows,

$$
E_{\text {total }}=2.05 \times 10^{-3} \mathrm{~W} \mathrm{~cm}^{-2} \times 4 \mathrm{~cm}^{2}=8.2 \times 10^{-3} \mathrm{~J} \mathrm{~s}^{-1}
$$

$\mathrm{N}_{\text {photons }}$ at $365 \mathrm{~nm}$ was calculated as follows,

$$
N_{\text {photons }}=\frac{E_{\text {total }}}{E_{\text {single photon }}}=\frac{8.2 \times 10^{-3} \mathrm{~J} \mathrm{~s}^{-1}}{5.44 \times 10^{-19} \mathrm{~J}}=1.5 \times 10^{16} \mathrm{~s}^{-1}
$$

The quantum yield was then calculated as follows,

$$
\eta=\frac{2 \times N_{\text {benzaldehyde }}}{N_{\text {photons }}} \times 100 \%=\frac{5.19 \times 10^{12}}{1.5 \times 10^{16}} \times 100 \%=0.069 \%
$$

The quantum yield of $m \mathrm{TiO}_{2}-600$, calculated using same method, is $0.029 \%$."

\section{Reference}

(1) Huang, P.; Huang, J.; Pantovich, S. A.; Carl, A. D.; Fenton, T. G.; Caputo, C. A.; Grimm, R. L.; Frenkel, A. I.; Li, G. Selective CO2 Reduction Catalyzed by Single Cobalt Sites on Carbon Nitride under Visible-Light Irradiation. J. Am. Chem. Soc. 2018, 140, 16042-16047. 